\title{
Review of: "Gulf Stream gyres may have dictated the outcome of the Covid-19 disease in Western Europe"
}

$\operatorname{Tim}$ X Lee

Potential competing interests: The author(s) declared that no potential competing interests exist.

Another fascinating read! Something to consider, warm ocean currents bring humidity. Increased humidity has been shown to reduce transmission rates. That could potentially be the mechanism.

Humidity could potentially be a factor in the phenomenon you mention in "A Covid-19 death trail connecting the Mediterranean with the North Sea, Italy with England, through the Alps" as well. Dry downslope winds by definition lack humidity and would increase transmission.

A couple of references on humidity and transmission rates.

https://onlinelibrary.wiley.com/doi/full/10.1111/tbed.13766

https://www.wfaa.com/article/news/health/coronavirus/could-high-humidity-slow-spread-coronavirus/287-6aa63537-1ed7-47efbaa4-64716d29c730

Again, I always enjoy reading your work! 